\title{
A EDUCAÇÃO DE JOVENS E ADULTOS NO ESTADO DO AMAPÁ: perspectivas e apontamentos sobre seu perfil atual
}

\author{
Valeria Silva de Moraes Novais \\ Mateus Paulino Ramos Gomes²
}

\section{RESUMO}

A Educação de Jovens e Adultos (EJA) é uma modalidade de ensino complexa que não se resume apenas à alfabetização inicial do aluno, mas dá a possibilidade ao educando à continuação dos estudos, haja vista que é um direito garantido pela Constituição Federal de 1988 e se caracteriza principalmente pela diversidade do seu público-alvo. Assim, o objetivo desse artigo é compreender e identificar as características da EJA no estado do Amapá, no que tange a distribuição de matrículas por etapa de ensino, faixa etária, cor/raça, sexo e sua relação com o processo de juvenilização dessa modalidade, no período de 2010 a 2016. Para a realização deste artigo, usou-se a abordagem qualitativa e a execução dos objetivos foi pautada na pesquisa documental. A metodologia foi dividida em três etapas: a primeira etapa compreendeu levantamento bibliográfico sobre o tema, a segunda etapa consistiu no levantamento e análise documental para coleta e sistematização dos dados e a terceira foi análise dos dados coletados e que permitiu traçar as características da EJA no estado do Amapá. A pesquisa mostrou que: a) o principal público da EJA nos dados coletados são jovens de 15 a 24 anos; b) as matrículas no setor privado vêm crescendo nos últimos anos e c) as matrículas no setor público vem diminuindo, a mesma tendência é identificada no cenário nacional.

Palavras-chave: Educação de jovens e adultos. Perfil do educando. Estado do Amapá.

\section{THE EDUCATION OF YOUNG PEOPLE AND ADULTS IN THE STATE OF AMAPÁ perspectives and notes about its current profile}

\begin{abstract}
The Education of Young People and Adults (EJA in Portuguese) is a complex teaching modality that can't be summarized into initial alphabetization pf the

1 Docente da Universidade do Estado do Amapá e no Programa de Pós-Graduação em Educação da Universidade Federal do Amapá. Lider do Grupo de Estudos e Pesquisa sobre Politicas Educacionais e Gestão - GEPPEG/UEAP. Orcid iD: https://orcid.org/0000-0003-35496213. E-mail: valeria.veap@yahoo.com.br

2 Graduando do Curso de Pedagogia na Universidade do Estado do Amapá. Orcid iD: https://orcid.org/0000-0002-9773-9076. E-mail: pawlinugomes@gmail.com
\end{abstract}

Revista Exitus, Santarém/PA, Vol. 9, № 5, P. 529 - 558, Edição Especial 2019. 
student only, but it gives the possibility to the professor to keep studying, considering that it's a right guaranted by the Federal Constitution of 1988 and it's mainly characterized by the diversity of its main public. Thus, the main of this paper is to comprehend and identify the EJA's characteristics in the State of Amapá, regarding the the distribution of enrollments by education stages, age range, skin color/race, gender, and its relationship with the juvenilization of this modality, in the term from 2010 to 2016. To perform this paper, it was used the qualitative approach and the performance of the objectives was ruled in the documental research. The methodology was divided into three stages: the first comprehended bibliographic gathering about the theme, the second stage was consisted in documental gathering and analyzes for data collection and systematization, and the third stage was analyzing the data collected, fact that made possible to outline EJA's charactheristics in the state of Amapá. With the research was possible to note that: a) EJA's main public in the collected data are young people from 15 to 24 years; b) the enrollments at the private sector have being increasing in the lasts years; $c$ ) the enrollments at the public sector have being decreasing, the same tendency is identified in the national scenario.

Keywords: Education of Young people and adults. Pupil profile. State of Amapá.

\section{LA EDUCACIÓN DE JÓVENES Y ADULTOS EN EL ESTADO DO AMAPÁ perspectivas y apuntes sobre su perfil actual}

\section{RÉSUMEN}

La educación de jóvenes y adulto (EJA) es una modalidad de enseñanza compleja que no se résumen sólo la alfabetización inicial del alumno, pero de la posibilidad al educando la continuación de los estudios, en vista de que es un derecho garantizado por la Constituición Federal de 1988 y se caracteriza principalmente por la diversidad de su público objetivo. Así, el objetivo de este artículo es comprender y identificar las características de la EJA en el estado de Amapá, en el que se refiere a la distribución de matrículas por etapa de enseñanza, grupo de edad, color / raza, sexo y su relación con el proceso de juvenilización de esa modalidad, en el período de 2010 a 2016. Para la realización de este artículo, se usó el abordaje cualitativo y la ejecución de los objetivos se basó en la investigación documental. La metodología se dividió en tres etapas: la primera la etapa comprendió levantamiento bibliográfico sobre el tema, la segunda etapa consistió en el análisis y análisis documental para la recolección y sistematización de los datos y la tercera fue análisis de los datos recogidos y que permitió trazar las características de la EJA en el estado del Amapá. La investigación mostró que: a) el principal público de la EJA en los datos recogidos son jóvenes de 15 a 24 años; b) las matriculaciones en el sector privado han crecido en los últimos años y c) las matriculaciones en el sector público están disminuyendo, la misma tendencia se identifica en el escenario nacional.

Palabras clave: Educación de jóvenes y adultos. Perfil del educando. Estado de Amapá. 


\section{INTRODUÇÃO}

A Educação de Jovens e Adultos (EJA) é uma modalidade de ensino essencial na vida de algumas pessoas, pois, através dessa conquista social, possibilitou a milhares de sujeitos que não tiveram oportunidade de frequentar a escola, pudessem ingressar, e este é um direito garantido na Constituição Federal de 1988.

Desde a década de 1990 com a aprovação da Lei de Diretrizes e Bases da Educação e a adoção da nomenclatura Educação de Jovens e Adultos - EJA, essa modalidade de ensino vem sofrendo alterações na constituição de sua identidade e perfil do educando e; tem se tornado crescente a entrada de jovens nessa modalidade de ensino, que outrora foi pensada principalmente para a alfabetização de adultos trabalhadores.

Sabe-se que a alfabetização de adultos vem ocorrendo no país desde o período colonial, e em determinados momentos históricos objetivou-se erradicar o analfabetismo, o que ainda não ocorrev, apesar da diminuição no número de analfabetos, dada as descontinuidades das ações governamentais para esse fim.

Entretanto, a partir da década de 1990, passou-se a notar uma crescente presença de jovens com idades de 15 anos em diante, na EJA (vale mencionar que nos dados oficiais do Censo da Educação Básica constam jovens com 14 anos de idade). Esses novos sujeitos apresentam, de modo geral, trajetórias escolares irregulares, com defasagens que se dá por inúmeros motivos, como: gravidez precoce, necessidade de trabalhar, entre vários outros fatores (HADDAD; DI PIERRO, 2000).

Apesar de estar estabelecido na Lei n. 9.394/96, a matrícula de jovens de 15 anos para cursar a EJA no Ensino Fundamental e a partir dos 18 anos para o Ensino Médio, a compreensão sobre esse público ainda provoca estranheza, devido às lutas históricas que o processo de alfabetização de adultos vivenciou e vem demarcando e fortalecendo o processo de juvenilização da EJA no país.

A relevância deste artigo está inserida numa conjuntura que demonstra a pouca discussão que vem sendo dada sobre a juvenilização da 
EJA e as alterações que ocasiona em incluir mais uma especificidade a um universo tão diverso como, historicamente, se construiu na EJA, principalmente, por ainda se acreditar que a EJA está ligada, em sua essência, a adultos e trabalhadores.

Diante desse cenário, nem tão recente, e da necessidade de aprofundarmos estudos e reflexões sobre as características da EJA na atualidade, faz-se urgente refletir e problematizar os delineamentos que a EJA vem vivenciando nos últimos anos e como vem se configurando o perfil dos educandos no estado do Amapá.

Frente às recentes orientações e características dessa modalidade de ensino, cabe, portanto, algumas questões norteadoras que precisam ser investigadas mais aprofundadamente: Como vem se constituindo a EJA no Brasil nos marcos legais das últimas décadas? Quais as características da EJA no Amapá, no que se refere à distribuição das matrículas por etapa de ensino, faixa etária, sexo e cor/raça? Como está se constituindo a juvenilização da EJA nos últimos anos no Amapá?

Diante dessas indagações, esse texto traz análises que buscaram respondê-las, considerando que não as esgotaremos frente à complexidade das problematizações que o fenômeno requer. Para tanto, objetivamos identificar e refletir sobre as características recentes da EJA no Amapá no que tange à distribuição de matrículas por etapa de ensino, faixa etária, sexo, cor/raça, no período de 2010 a 2016.

Consideramos que a EJA possui especificidades de diferentes ordens, como a faixa etária diversa, o contexto sociocultural e educacional dos sujeitos educandos que a frequentam, e as políticas voltadas para esta e a histórica luta em constituir uma identidade que realmente contemple as suas múltiplas especificidades, logo, as alterações no perfil e a ampliação de adolescentes na EJA, se configura enquanto um elemento que precisa ser refletido e implica diretamente na constituição da atual realidade dessa modalidade no país.

Faz-se urgente ampliar e reconhecer que a juvenilização da EJA adiciona uma visão de mundo de pessoas que tem características e tempos

Revista Exitus, Santarém/PA, Vol. 9, № 5, p. 529 - 558, Edição Especial 2019. 
biológicos, psicológicos e sociológicos diferentes de um adulto ou idoso, e para tanto, exige particularidades no seu processo educativo, além de uma condição social, racial e cultural específicas, que precisam estar claras para que a escola tenha condição de se adaptar a diversidade que a EJA requer.

Para a realização deste artigo, usou-se a abordagem qualitativa e a execução dos objetivos propostos realizou-se a pesquisa documental, que segundo Gil (2008, p. 70) é um tipo que "(...) vale-se de materiais que não receberam ainda um tratamento analítico, ou que ainda podem ser reelaborados de acordo com os objetivos da pesquisa".

No que tange a operacionalização metodológica empregada, esta pesquisa foi dividida em três etapas. A primeira etapa compreendeu um levantamento bibliográfico sobre o tema, a segunda etapa consistiu no levantamento e análise documental para coleta dos dados e a terceira e última etapa foi a estruturação para a sistematização e análise dos dados e que permitiu traçar as características da EJA no Estado do Amapá.

Esse artigo está estruturado em três partes além desta introdução. Primeiramente, fazemos um breve histórico da EJA no Brasil e como se inseriu na política educacional. Em seguida, realizamos uma discussão acerca do perfil sociocultural do educando da EJA e como determinados marcos legais interferiram nas perspectivas e caracteriticas atuais. Na terceira seção, apresentamos dados acerca das características da EJA no Brasil, no Norte e em especial no Amapá.

\section{Visões de educando da EJA nas políticas educacionais: breve contextualização}

A Educação de Jovens e Adultos no Brasil iniciou-se de forma tardia, historicamente, marcada por características assistencialistas, onde desde a colonização o processo educacional foi assumido pelos Jesuítas que tinham por objetivo catequização e ensino das primeiras letras aos índios, por meio de preceitos religiosos, ensinando-lhes normas de comportamentos, ofícios necessários ao funcionamento da economia colonial. Como a maioria da 
população era analfabeta, as aulas eram ministradas oralmente. Nascimento $(2013$, p. 15) sobre essa situação destaca o seguinte:

(...) na época de colonização do Brasil, somente as classes médias e altas tinham acesso ao conhecimento nas poucas escolas que existiam, os filhos recebiam atendimento escolar em casa, não havia a necessidade de alfabetizar jovens e adultos, a classe pobre era desfavorecida não tinha nenhum acesso à escola e quando ocorria era de forma indireta.

O cenário educacional da época caracterizou-se pelo elitismo em que somente as classes mais abastadas tinham acesso à educação. Paiva (1987) observou os registros históricos educacionais e notou que no Brasil durante quatro séculos, constitui-se o "domínio da cultura branca, cristã, masculina e alfabetizada sobre a cultura de índios, negros, mulheres e analfabetos", o que sucedeu uma "educação seletiva, discriminatória e excludente." Com a expulsão dos jesuítas em 1759, o processo educacional entra em declínio, ficando assim, a mercê do governo imperial.

Durante muitas décadas, pouco se fez tanto pela educação quanto para a alfabetização de adultos, que atingia percentuais elevados da população nacional. Vale ressaltar que a Constituição de 1824, no artigo 179 procurou ampliar a instrução primaria a todos os cidadãos, no entanto, isso na prática não ocorreu. De acordo com o Parecer CNE/CEB n 11/2000:

(...) A titularidade da cidadania era restrita aos livres e aos libertos. Num país pouco povoado, agrícola, esparso e escravocrata, a educação escolar não era prioridade política e nem objeto de uma expansão sistemática. Se isto valia para a educação escolar de crianças, quanto mais para adolescente, jovens e adultos (PARECER CNE/CEB, 2000, p. 12).

Em conformidade, o analfabeto era visto como um sujeito incapaz de exercer a sua cidadania, o que aumentava ainda mais o preconceito, que prevaleceu nas décadas seguintes. A década de 1930 teve como marco a reafirmação da necessidade de um Plano Nacional de Educação, instituído na Constituição de 1934, na qual estabeleceu-se que é dever do Estado o ensino primário integral, gratuito de frequência obrigatória e extensiva para 
adultos como direito constitucional, todavia, foi considerado elementar porque passou a ser ofertado principalmente pelos elevados índices de analfabetismo no país.

De acordo com Soek (2012, p.14) relata (...) "Oferecer educação também para adultos, rompia com o estigma social da época de que a escola só era necessária somente às crianças". Nesse contexto, o Brasil passava por várias transformações tanto políticas, econômica, sociais e culturais, por conta da ascensão industrial urbana, sucedendo as elites rurais, surgia assim, uma nova configuração da acumulação capitalista no país. Cunha, Damasceno e Cortez (2012, p.4) ressaltam que:

$\mathrm{Na}$ década de 30, a educação passa a ser pensada como um projeto de classes sociais. Como a característica mais evidente nessa época eram os interesses voltados à industrialização, o sistema de ensino passou a ser identificado como educação para o trabalho. A preocupação educacional era a qualificação técnica para o desenvolvimento industrial. Com isso a educação fica restrita a mera qualificação profissional.

Dessa forma, a Educação de Jovens e Adultos no país surgiu como uma alternativa à qualificação da mão de obra, com finalidade à demanda industrial que vinha crescendo. No entanto, a Constituição de 1937 apresentou alguns retrocessos na educação, devido ao golpe de Getúlio Vargas (1937-1945 - período conhecido como Estado Novo), tendo como finalidade organizar o Estado aos ditames do setor industrial em virtude da decorrência da primeira guerra mundial. De acordo com Ghiraldelli Jr (2008, p.78):

\begin{abstract}
A Constituição de 1937 fez o Estado abrir mão da responsabilidade para com a educação pública, uma vez que ela afirmava o Estado como quem desempenharia um papel subsidiário, e não central, em relação ao ensino. O ordenamento democrático alcançado em 1934 quando a letra da lei determinou a educação como direito de todos e obrigação dos poderes públicos, foi substituído por um texto que desobrigou o Estado de manter e expandir o ensino público.
\end{abstract}

Com o intuito de beneficiar o Estado, retirando toda a sua responsabilidade, a formulação da Constituição de 1937, favoreceu o ensino 
profissionalizante, com o objetivo de capacitar os jovens para trabalhar nas indústrias, sem a mínima preocupação de disseminar o conhecimento científico, evidenciando que a educação seria para poucos, pois o povo sem educação estaria passível ao que lhe era imposto (NASCIMENTO, 2013).

Com o fim da ditadura de Getúlio Vargas em 1945, o país passou pelo processo de redemocratização tanto político como educacional, todavia, no país os índices de analfabetismo continuavam altos, o que demandou por parte do poder público, medidas cabíveis para extinguir ou reduzir os elevados índices. Nascimento (2013) enfatiza que:

O crescimento da industrialização atraiu aos centros urbanos migrações da zona rural, os que migravam tinham a expectativa de melhorar a qualidade de vida, esses trabalhadores precisavam ser alfabetizados, o que demandou o crescimento de alfabetização de Jovens e adultos.

Ainda sobre esse período, Soek (2012, p, 18) enfatizava que: "era urgente à necessidade de aumentar as bases eleitorais para a sustentação do governo central, integrar o contingente imigratório, (...). Portanto, era primordial oferecer instrução mínima à população". Em virtude dessa situação, no ano 1947 surge a primeira Campanha de Educação de Adolescentes e Adultos (CEAA) com proporção nacional. Nesse contexto, a educação de adultos passou a ser tratada como problema educacional.

Essa campanha, idealizada por Lourenço Filho, tinha por objetivo levar educação básica a todos os brasileiros iletrados, tanto nas áreas urbanas como rurais, com pretensão de alfabetizar o adulto analfabeto em três meses, disponibilizando o curso primário em duas etapas de sete meses, com o intuito de elevar níveis educacionais e tornar acessível o direito de educação negado aos jovens e adultos. Sobre essa campanha, Di Pierro, Joia e Ribeiro (2001, p.60) citam que:

A campanha de 1947 deu também lugar à instauração no Brasil de um campo de reflexão pedagógica em torno do analfabetismo e suas consequências psicossociais; entretanto, ela não chegou a produzir nenhuma proposta metodológica específica para a alfabetização de adultos, nem um paradigma pedagógico próprio para essa modalidade de ensino. 
Em consonância com que foi dito, a educação para jovens e adultos não é somente aprendizagem da leitura, escrita, e cálculos matemáticos, é uma modalidade onde o aprendizado acontece de maneira formal e informal, indo além dos espaços escolares e não escolares, levando em consideração toda uma estrutura social e o contexto na qual o aluno está inserido (SOUZA; SILVA, 2011). Desta forma, necessitava-se de uma metodologia educacional eficiente, que tratasse o educando como um sujeito ativo, capaz de transformar sua realidade existencial.

Durante esse período, foi criada também a Campanha de Educação Rural (CNER-1952), e a Campanha Nacional de Erradicação do Analfabetismo (CNEA-1958). Tais campanhas foram temporárias e ineficazes, "(...) mesmo que inserida dentro da vertente da educação popular, era muito mais em diminuir índices de analfabetismo, do que com a qualidade da educação e emancipação política e cultural da população" (SOEK,2012, p.19).

$\mathrm{Na}$ década de 1960, surgiu um novo paradigma educacional brasileiro, fundamentado nas ideias e experiências de Paulo Freire, que juntamente com diversos setores da sociedade civil, entre eles sindicatos, destacam-se, o Programa do Movimento de Educação de Base (MEB), ligado à Conferência Nacional dos Bispos do Brasil (CNBB), Movimento de Cultura Popular do Recife (1960), Centros Populares de Cultura da União Nacional dos Estudantes (1961), toda essa mobilização social envolvida pela efervescência política e cultural da época, resultou em uma nova concepção educacional pautada nos paradigmas freireanos. Portanto, "Professava a necessidade de realizar uma educação crítica, voltada a transformação social e não apenas a adaptação da população a processos de modernização conduzidos por forças exógenas". (DI PIERRO; JOIA; RIBEIRO, 2001, p.60).

No entanto, todo progresso educacional alcançado até então foi suprimido pelo golpe militar de 1964 que desestruturou e reprimiu todos os movimentos de educação e cultura popular, inclusive os métodos 
inovadores teóricos e pedagógicos de Paulo Freire para a educação de adultos.

Em 1967, o governo militar cria o Movimento Brasileiro de Alfabetização (MOBRAL) investindo em grandes recursos financeiros, atuando em todo 0 território brasileiro, possuindo autonomia em relação às Secretarias Estaduais e Ministério da Educação, no qual "comissões municipais se responsabilizavam pela execução das atividades, enquanto que a orientação geral, a supervisão e a produção de material pedagógico eram centralizados" (SOARES, 2010, p, 103).

Dentre todas essas características, a metodologia pedagógica do MOBRAL não possuía caráter crítico e problematizador do "método Paulo freire". Diversificando sua atuação ao longo dos anos 70. Contudo, logo na década de 1980, em declínio o regime autoritário em 1985, o MOBRAL é extinto por conta de várias críticas quanto a sua metodologia e ineficácia na alfabetização de jovens e adultos.

Vale ressaltar que a Lei $n^{\circ} 5.692 / 71$ priorizou um capítulo ao Ensino Supletivo, sobre isso, Ribeiro (2017) cita que o ensino supletivo foi apenas criado como uma modalidade temporária para os que precisavam comprovar escolaridade no trabalho e para os analfabetos. Entretanto, o temporário tornou permanente por longos anos, pois em conformidade, o Parecer n 699/72 do Conselho Nacional de Educação (CNE) destacou quatro funções do Ensino Supletivo, as quais são:

1) Suplência (substituição compensatória do ensino regular pelo supletivo via cursos e exames com direito a certificação de ensino de $1^{\circ}$ grau para maiores de 18 anos e de ensino de $2^{\circ}$ grau para maiores de 21 anos); 2) Suprimento (completação do inacabado por meio de cursos de aperfeiçoamento e de atualização); 3) Aprendizagem; 4) Qualificação (apud SOARES, 2002).

O capítulo IV da Lei $n^{\circ} 5.692 / 71$, destina-se a descrever as finalidades, as formas como ocorrerá sua realização, os objetivos do Ensino Supletivo dentre outros aspectos. Sobre as finalidades o artigo 24 diz: 
a) Suprir a escolarização regular para os adolescentes e adultos que não a tenham seguido ou concluído na idade própria;

b) Proporcionar, mediante repetida volta à escola, estudos de aperfeiçoamento ou atualização para os que tenham seguido 0 ensino regular no todo ou em parte (apud SOARES, 2002).

Com isso, verifica-se que o Ensino Supletivo se mantém atualmente, como se vê, por meio da Educação de Jovens e Adultos, Exame para Certificação de Competências de Jovens e Adultos - ENCCEJA, que buscam justamente suprir a carência de escolarização de jovens e adultos, e que por vários motivos não concluíram o Ensino Fundamental ou Médio no período adequado.

Em substituição ao MOBRAL em 1985, surgiu a Fundação Educar que executava diretamente os programas, todavia, apoiava tecnicamente e financeiramente as ações de alfabetização, no entanto, foi extinta em 1990, no início do governo Collor, quando preconizava uma nova concepção de educação para jovens e adultos, a partir da Constituição Federal de 1988.

Já no que se refere à EJA e seus aspectos mais atuais, verifica-se que de acordo com Machado (1998), no que diz respeito ao tão propagado Ano Internacional da Alfabetização, que foi em 1990, foram realizados em todo país diversos debates, encontros, congressos e seminários por entidades governamentais e não governamentais, no sentido de discutir e apresentar propostas para a erradicação do analfabetismo no Brasil. Neste mesmo ano, - Governo Collor lançou o Programa Nacional de Alfabetização e Cidadania (PNAC) que pretendia reduzir em $70 \%$, o número de analfabetos no país nos 5 anos seguintes, e como era de se esperar, o programa passou por diversos problemas, que iam desde formação adequada de quem trabalhava nesse programa à administração dos recursos.

Após Itamar Franco assumir a presidência, no que se refere à EJA, vai se tentar um fortalecimento da discussão que vinha se dando em torno da implementação de um programa sistemático, não apenas de alfabetização, mas de garantia do Ensino Fundamental para Jovens e Adultos, prova disto é uma nova composição na Comissão Nacional com educadores que coordenaram os debates desta temática, em torno do Plano Decenal de 
Educação para Todos 1993/2003, ao mesmo tempo em que já vinham realizando discussões para o projeto de Lei de Diretrizes e Bases da Educação Nacional - LDB (MACHADO, 1998).

Como já visto, a história da EJA no Brasil configurou-se uma luta social contra o analfabetismo que permeou durante muito tempo e ainda persiste nos dias atuais, desde a primeira constituição monárquica e outras leis criadas no decorrer da história à promessa era educar a todos, no entanto pouco se fez.

A indústria no século passado, com escassez de mão de obra especializada, procurou dar incentivo à educação de adultos, tanto nas áreas urbanas como rurais. O Regime Militar, por sua vez, reprimiu os movimentos de educação popular impondo uma educação conservadora, assistencialista e tecnicista, desfazendo todo trabalho pedagógico para a Educação de Jovens e Adultos alcançado nas décadas de 50 e 60 . A constituição de 1988 foi um passo significativo na consolidação do direito à Educação de Jovens e Adultos, reafirmada na LDB de 1996.

Portanto, verificamos que a EJA surgiu como modalidade de ensino no ano de 1990 e, a partir desse período passou, por um longo processo de lutas e conquistas, que se deram por meio de movimentos, encontros, aprovação de leis, pareceres, etc. Assim, em decorrência das várias transformações das perspectivas educacionais, materializadas nas políticas educacionais para jovens e adultos ao longo dos anos, algumas características ficaram marcantes: o assistencialismo, a descontinuidade e a exclusão estiveram presentes nas ações, as quais refletem ainda na falta de uma identidade para a EJA e, consequentemente, implica na constituição de seu perfil. Esse cenário sucscita uma reflexão sobre quem são essas pessoas que procuram as salas de EJA. Dentre essa e outras questões serão debatidas no tópico seguinte.

\section{Perfil do educando da EJA na atualidade: a influência dos marcos legais}

Conhecer a história da EJA e seu processo de formação é essencial para traçar a identidade e o perfil que se quer alcançar. Assim, é necessário 
levar em consideração as histórias de vida das pessoas da EJA, sua faixa etária, nível de escolaridade em que parou de estudar, idade, sexo, cor/raça, entre outras especificidades que compõem o público atendido nessa modalidade, pois todos esses dados servem como parâmetros para superação de problemas atuais ou até mesmo os que continuam desde que se pensou em alfabetizar jovens e adultos. Nesse sentido, verificada a importância de se conhecer a história da Educação da EJA, as autoras Monteiro e Moura (2012, p. 3) afirmam que:

\begin{abstract}
A Educação de Jovens e Adultos vem tentando durante um longo período, se configurar como uma educação que possa atender de fato as especificidades do público que buscam retornar ou até mesmo na chegada pela primeira vez à escola uma possibilidade de mudança social e de integração na sociedade "letrada".
\end{abstract}

Em concordância, Dias (2017, p.196) afirma que a educação é fenômeno essencial para a existência humana, e "Ocorre como qualidade ontológica com a qual os seres humanos se fazem se refazem 'no' e 'com' o mundo ao mesmo tempo em que se dá de maneira permanente na história". Diante disso, mediada pela educação, uma pessoa que não teve acesso na idade regular, pode a qualquer tempo da vida aprender e atender as necessidades de sua existência.

No que se refere ao perfil do educando da EJA, é notório que há uma diversidade de pessoas com diferentes faixas etárias e culturas diversificadas, que tem como objetivo comum a busca pelas oportunidades educativas, com a finalidade de atender suas necessidades básicas de aprendizagem. Soares $(2002$, p.77) cita dois perfis do educando EJA:

(..) São jovens e adultos, muitos deles trabalhadores maduros, com larga experiência profissional ou com expectativa de (re)inserção no mercado de trabalho e com um olhar diferenciado sobre as coisas da existência, que não tiveram diante de si (...) para eles, foi a ausência de uma escola ou a evasão da mesma que os dirigiu para um retorno nem sempre tardio à busca do direito ao saber. Outros são jovens provindos de estratos privilegiados e que, mesmo tendo condições financeiras, não lograram sucesso nos estudos, em geral por razões de caráter sociocultural.

Revista Exitus, Santarém/PA, Vol. 9, № 5, P. 529 - 558, Edição Especial 2019. 
Ao analisar várias dissertações e teses de doutorados, a autora Maria Margarida Machado (2002) chega a algumas conclusões que ratificam um perfil já conhecido entre os alunos jovens e adultos e estas são listadas a seguir:

a) São indivíduos que, juntamente com seus familiares, estão marcados por "carências" socioeconômicas e culturais. Como alunos, além da carência material, apresentam também carências afetivas e falta de participação nos processos de decisão dos rumos que serão dados ao seu destino profissional e societário (Guimarães, 1990). Há uma inserção cada vez maior de mulheres (Silva, 1998) e jovens (Marques, 1995) nos programas de EJA. b) A escola reproduz a estrutura de desigualdade social presente na sociedade capitalista; está longe da realidade e das necessidades concretas dos alunos. Daí resultam repetência, evasão e fracasso, muito evidenciados entre os jovens que cada vez mais ocupam as escolas noturnas (Fiker, 1989). Os conteúdos e metodologias partem de um padrão de aluno "ilusório" (Freitas, J. R., 1994; Freitas, M. V., 1995). Por outro lado, não se pode desconsiderar que a escola noturna é marginalizada, a freqüência às aulas é prejudicada pela falta de professores, os serviços de apoio pedagógico são inexistentes, o relacionamento com o corpo administrativo não é cordial (Nunes, 1995). As experiências de cursos e exames supletivos reforçam esta marginalidade da Educação de Jovens e Adultos, segundo os autores. c) Da parte dos alunos, muitos se consideram incapazes e fracos, introjetando a concepção da ideologia dominante do fracasso entre alunos do noturno como inevitável (Kalaf, 1990). Esta concepção também é visível entre alunos oriundos da zona rural. d) Foi identificada, também, entre os alunos do noturno, principalmente no ensino mé- dio, uma visão individualista e utilitarista da educação. A escola deve certificar e preparar para o trabalho - nada mais (Pereira, 1995). Já entre os mais jovens, ainda há uma busca do processo de socialização na escola, tão difícil de se dar no âmbito das comunidades locais (Marques, 1995). e) Ainda com relação ao mundo trabalho, podem ser identificadas conclusões contrárias quanto a sua relação com a escolarização. Enquanto para os alfabetizandos das experiências de Brasília (Queiroz, 1993) alfabetizar-se significa manutenção do emprego e melhor integração social, para os alunos do curso noturno investigado por Reginato (1995) o trabalho é o principal fator de exclusão escolar, pois, em função do cansaço e do ritmo pesado no emprego, muitos abandonam a escola. Outra experiência que se destaca nesta temática "mundo do trabalho" é a pesquisa de Manzano (1989) sobre a escola da Volkswagen, onde os alunos demonstram possuir consciência de que os efeitos escolares são mais importantes do que os dos treinamentos, pois o saber apropriado se constitui um patrimônio (MACHADO, 2002, p.5152). 
Dado o exposto, é fundamental que a EJA supere as barreiras e as desigualdades que ainda prevalecem no contexto atual, que torne esse direito subjetivo acessível, proporcionando uma educação de qualidade a toda a população. Oliveira (2011) salienta que:

\begin{abstract}
Sem negar o direito de todos à educação, as políticas da EJA precisam priorizar a superação da exclusão educacional de jovens e adultos e idosos pertencentes às classes populares, negados no seu direito constitucional de acesso ao sistema escolar (2011, p.13).
\end{abstract}

Para evidenciar o pensamento da autora sobre a Desigualdade Social e exclusão, os dados estatísticos, segundo o IBGE (2016), mostram que a taxa de analfabetismo de pessoas de 15 anos ou mais idade corresponde a 7,2\% e equivale ao contingente de 11,8 milhões de analfabetos. Na faixa de 60 anos ou mais, o percentual atingiu 20,4\%. Diante disso, vê-se a necessidade de reafirmar as vertentes do Documento Marco de Ação em Belém (2010), o qual aponta para a redução do analfabetismo, focar para as ações de alfabetização em um específico segmento social, como as mulheres, povos indígenas, pessoas privadas de liberdade, educandos com necessidade educacionais especiais e populações rurais.

Além da especificidade sociocultural, como as apontadas no documento supracitado, a especificidade etária veio caracterizando traços mais marcantes do perfil do educando da EJA desde a década de 1990, até os dias atuais. Para tanto, um conjunto de marcos legais são ou foram de relevância no que diz respeito à EJA, principalmente, na definição do que se considera jovem, adulto e idoso, e é importante ressaltar o conceito de jovens e adultos perante as instituições.

De acordo com o Estatuto da Criança e do Adolescente - ECA, criado pela Lei n. 8.069 no ano de 1990, pelo então presidente Fernando Collor de Melo, essa legislação considera jovens, pessoas acima de 18 anos e abrange um conjunto de medidas com o objetivo de proteger e cuidar dos indivíduos menores: crianças (até 12 anos incompletos) e adolescentes (de 12 a 18 anos incompletos). 
A Organização das Nações unidas - ONU considera juvens as pessoas que têm entre 15 e 24 anos de idade. Enquanto que, de acordo com a Lei estadual $n^{\circ} 2.222$, de 21 de agosto de 2017, criado pelo Governador do Amapá, Waldez Góes, considera em seu artigo $2^{\circ}$

O Conselho Estadual de Juventude do Amapá (CEJUVE) tem por finalidade formular e propor diretrizes da ação governamental, voltadas à promoção de políticas públicas para jovens de 15 (quinze) a 29 (vinte e nove) anos", além de proceder e intervir de forma consultiva, deliberativa e fiscalizadora, de acordo com a Constituição Brasileira e o Estatuto da Juventude (AMAPÁ, 2017).

O Instituto Brasileiro de Geografia e Estatística - IBGE (2016) define como jovem a população dos 15 aos 24 anos. Sob esses parâmetros, os jovens ocupam, hoje, um quarto da população do país. Isso significa que 51,3 milhões de jovens de 15 a 29 anos vivendo, atualmente, no Brasil, sendo $84,8 \%$ nas cidades e $15,2 \%$ no campo. A pesquisa mostrou que $53,5 \%$ dos jovens de 15 a 29 anos trabalham, 36\% estudam e 22, $8 \%$ trabalham e estudam simultaneamente.

No que diz respeito ao adulto é a pessoa na faixa etária dos 18 aos 60 anos, tomando como referência o Estatuto da Criança e do Adolescente (1990), que considera o fim da adolescência aos 18 anos, e o Estatuto do Idoso (2003), que define a pessoa idosa aquela que tem 60 anos ou mais. Para Silva (2004), a vida adulta compreende três períodos: adulto jovem, para a faixa etária entre 18 e 21 anos, adulto, para a faixa etária de 21 aos 45 anos, e meia-idade, para as pessoas que possuem idade entre 45 e 60 anos.

Como se pode observar, anteriormente, a EJA passou por um longo processo de mudanças até os dias atuais seja nas ações da política educacional, seja na constituição do perfil do educando. As mudanças na área da educação se deram por meio da Lei de Diretrizes e Bases da Educação - LDB que instituiu a EJA como modalidade de ensino e reduziu a idade para acesso a tal modalidade. É importante destacar, ainda, que as legislações que organizaram a estrutura da EJA que se tem hoje, e as principais políticas que articulam a Educação de Jovens e Adultos e 
Educação profissional colaboraram para a entrada e permanência do jovem na EJA.

Muitos são os fatores que contribuem para a crescente juvenilização na rede pública de ensino, dentre os quais se podem citar, a gravidez na adolescência, ingresso precoce no mercado de trabalho, o ingresso no mundo do crime, a defasagem idade-série e a possibilidade de acelerar os estudos. Sobre esses fatores Carvalho $(2009$, p.2) destaca o seguinte:

(...) as deficiências do sistema de ensino regular público, como a evasão, repetência, que ocasionam a defasagem entre a idade/série, a possibilidade de aceleração de estudos (como o fato de concluir em menor tempo o Ensino Fundamental e Médio) e a necessidade do emprego, contribuem para a migração dos jovens à EJA.

Neste contexto, o autor evidencia que as deficiências no sistema de ensino foram crucias para a crescente presença da juventude na EJA, pois segundo ele "os jovens são configurados como adultos em função da forma concreta como vivenciam seu tempo de juventude", assim sendo, ele acrescenta que estes são "jovens na idade, mas tornados adultos pelas regras sociais que não thes oportunizou viver seus direitos: direito à educação, à identidade, ao desenvolvimento pleno e à juventude" (CARVALHO, 2009, p.5).

Diante do exposto, o perfil do educando da EJA tem se tornado mais diversificado, pois pensar no público dessa modalidade é necessário considerarmos aspectos étnicos, culturais, econômicos, sociais e etários. Tais especificidades não podem ser apenas em caráter informativo ou para fins de identificar características gerais, mas, principalmente, deve circundar todas as ações realizadas ao longo do processo educativo de um sujeito. Um jovem, adulto ou idoso possui particularidades que aliadas às diferenças culturais, econômicas e sociais, reverberam no processo de ensinoaprendizagem destes. Para Dias (2017, p. 197), é preciso pensar uma

Educação que agrega as diferenças de todas as ordens: intergeracionais, étnicas, culturais, diferenças de lógicas de tempo, 
de espaços: urbanos, ribeirinhos, quilombolas, comunidades extrativistas, de agricultores, entre tantas outras.

Portanto, a EJA não possui um perfil, mas, perfis que se ampliam na medida em que a sociedade capitalista se complexifica e altera a formação e identidade social e, consequentemente, adiciona novas ou outras caracteristicas. A EJA da atualidade é do jovem trabalhador ou não, do idoso aposentado ou mesmo (na informalidade) ainda está trabalhando, do adulto indígena ou rural, entre tantas possibilidades de especificidades que não podem ser ignoradas e não ser consideradas no processo educativo e nas formulações das ações das políticas educacionais.

\section{A EJA no Estado do Amapá: o que os dados revelam}

Este tópico tem como objetivo analisar o perfil (ou perfis) da EJA no Amapá, por etapa de ensino, faixa etária, sexo e cor/raça, e como tais caracterisiticas constituem as particularidades dessa modalidade no estado.

Para uma melhor compreensão de EJA no estado do Amapá, é importante fazer uma breve análise histórica de como surgiu essa modalidade de ensino, de acordo com Soares et al. (2010) a educação de jovens e adultos começa a ser ofertada a partir de 1973, na qual o Conselho de Educação do Território do Amapá - CETA, cria a resolução n 01/73, dispondo normas para a oferta dos exames de educação geral de $1^{\circ}$ e $2^{\circ}$ grau, no período em que o atual Estado era organizado como território federal e administrado pela União.

Dado o exposto, a EJA no estado do Amapá vem crescendo e afirmando o direito pela educação àqueles que não tiveram acesso na idade certa. Assim como no Amapá e no Brasil, a educação de jovens e adultos é um campo complexo e diversificado, como afirma Silva (2009) "É no cotidiano das práticas de EJA que a diversidade cultural, étnica, racial e de gênero se expressam", e vale destacar que nesse estado há uma forte presença de etnias indígenas e comunidades quilombolas distribuídas nos municípios amapaenses. 
No tocante ao processo de juvenilização da EJA não é um fenômeno recente no País, como citam Haddad e Di Pierro (2000)

\begin{abstract}
A partir dos anos 80, os programas de escolarização de adultos passaram a acolher um novo grupo social constituído por jovens de origem urbana, cuja trajetória escolar foi malsucedida. O primeiro grupo vê na escola uma perspectiva de integração sociocultural; o segundo mantém com ela uma relação de tensão e conflito aprendida na experiência anterior (HADDAD; PIERRO, 2000, p.127).
\end{abstract}

Como já debatido nos tópicos anteriores, e reforçado pelos autores acima é inegável o quanto a EJA vem se transformando ao longo dos anos, principalmente seu público "(...) A educação de Jovens e adultos não é a mesma coisa de décadas passadas, a qual tinha como cenário de sala de aula a maioria de alunos adultos e um número mínimo de jovens" (CARVALHO, 2009). Nessa direção, a Tabela 1 abaixo apresenta os dados acerca das matrículas na EJA, por faixa etária nos anos de2015 e 2016 . Em seguida,

TABELA 1- Matrículas na EJA por faixa etária no Brasil, Norte e Amapá - 2015 e 2016

\begin{tabular}{c|c|c|c|c|c|c}
\cline { 2 - 7 } FAIXA ETÁRIA & \multicolumn{2}{|c|}{ BRASIL } & \multicolumn{2}{c|}{ NORTE } & \multicolumn{2}{c}{ AMAPÁ } \\
\cline { 2 - 7 } & $\mathbf{2 0 1 5}$ & $\mathbf{2 0 1 6}$ & $\mathbf{2 0 1 5}$ & $\mathbf{2 0 1 6}$ & $\mathbf{2 0 1 5}$ & $\mathbf{2 0 1 6}$ \\
\hline Até 14 & 26.688 & 20.656 & 4.271 & 3.159 & 238 & 154 \\
\hline 15 A 17 & 611.189 & 576.806 & 98.242 & 88.619 & 6.365 & 5.818 \\
\hline 18 A 19 & 564.249 & 589.113 & 80.774 & 76.975 & 5.041 & 5.250 \\
\hline 20 A 24 & 673.360 & 723.850 & 92.325 & 90.625 & 4.914 & 5.413 \\
\hline 25 A 29 & 359.969 & 357.456 & 51.288 & 45.570 & 2.321 & 2.244 \\
\hline 30 A 34 & 300.810 & 288.738 & 40.582 & 35.603 & 1.586 & 1.586 \\
\hline 35 A 39 & 281.139 & 265.202 & 31.928 & 28.035 & 1.191 & 1.179 \\
\hline 40 ou mais & $\mathbf{6 7 4 . 4 6 5}$ & 660.353 & 55.722 & 49.810 & 2.135 & 2.056 \\
\hline TOTAL & $\mathbf{3 . 4 9 1 . 8 6 9}$ & $\mathbf{3 . 4 8 2 . 1 7 4}$ & $\mathbf{4 5 5 . 1 3 2}$ & $\mathbf{4 1 8 . 3 9 6}$ & $\mathbf{2 3 . 7 9 1}$ & $\mathbf{2 3 . 7 0 0}$ \\
\hline
\end{tabular}

Fonte: INEP - Sinopse Estatística da Educação Básica, 2015 e 2016.

Nota: Nas sinopses estatísticas anteriores a 2015 não é informado os dados sobre matrícula por faixa etária.

Na tabela 1, no que tange o número de matrículas no Brasil, nota-se uma diminuição em quase todas as faixas etárias, exceto entre a população 
de 18 a 19 anos e 20 a 24, e a maioria dessas matrículas atende pessoas entre 20 a 24 e 40 anos ou mais. Na região Norte todas as faixas etárias tiveram diminuição de matrículas entre 2015 e 2016 e a maior parte das matrículas atendem pessoas de 15 a 24 anos. Já no Amapá, a maioria das faixas etárias cresceu em quantidade (18 a 24 anos; 30 a 39 anos), na população até 14 anos, 15 a 17 anos e 40 anos ou mais, houve diminuição nas matrículas. Vale destacar que nesse estado, o maior quantitativo de matrículas atende pessoas de 15 a 24 anos.

É indispensável destacar a diminuição das matriculas entre esses anos, fato esse que vem ocorrendo no país nos últimos anos. Na região Norte essa diminuição foi maior. De modo geral, é perceptível que as matrículas da EJA estão diminuindo, o que vem provocando inquietação entre os pesquisadores da temática. Sobre essa diminuição, Di Pierro (2016) destaca algumas hipóteses para responder essa indagação:

A primeira delas tem a ver com o mercado de trabalho. Durante 0 período em que a economia e as taxas de emprego cresceram, o mercado absorveu mão de obra mesmo com baixa qualificação, segundo dados do Pnad [Pesquisa Nacional por Amostra de Domicílios]. Ou seja, a pressão no mercado de trabalho não estaria operando em favor de as pessoas retomarem o estudo. [...]. A segunda hipótese é que ainda não construímos uma cultura do direito à educação ao longo da vida. O mesmo não acontece com a cultura do direito à educação na infância e na adolescência, que vem sendo construída desde a redemocratização. Hoje, é inaceitável que uma criança esteja fora da escola na chamada idade escolar. Uma mãe analfabeta, com muito baixa escolaridade, vai brigar pelo direito do filho a ter uma vaga na escola. Mas provavelmente não brigará pelo dela. Ela não se vê como alguém que tem direito à educação.

Um fato que chama atenção é quanto às matrículas de pessoas com até 14 anos de idade, que contraria a determinação da LDB, que estabelece a idade mínima de 15 anos para o ensino fundamental e 18 anos para o ensino médio. Entretanto, foram matrículadas 20.656 pessoas no Brasil, 3.159 no Norte e 154 no Amapá, em 2016.

Outro aspecto que merece destaque é quanto à matrícula de pessoas adultas ou idosas analfabetas. Se confrontarmos com os dados da Pesquisa 
Nacional por Amostra de Domicílio - PNAD (2016), na tabela 1, é possível identificar que a oferta de EJA não está atendendo a parcela da população adulta e idosa que necessita de alfabetização, uma vez que é exatamente esse público que precisa estar nas salas de aula da EJA. Os dados evidenciam o aumento nos índices de analfabetismo nas faixas etárias de 40 ou mais (12,3\%) e 60 anos ou mais $(20,4 \%)$.

A partir da realidade dos alunos matriculados da EJA, no ano de 2016 no estado do Amapá, se somarmos os alunos matriculados, de 30 anos ou mais de 40 anos, ainda assim, não se alcança o número de alunos entre idades de 15 e 17. É notório, portanto, que a realidade constatada é a juvenilização da EJA.

Na tabela 02 e 03 apresentam-se as matrículas por sexo e cor/raça no Brasil, Norte e Amapá e nota-se um predomínio do sexo masculino e pessoas que não declararam sua cor/raça, em todas as regiões geográficas analisadas entre 2015 e 2016.

TABELA 2 - Número de Matrículas na EJA, do Sexo Masculino por Cor/Raça Brasil, Norte e Amapá - 2015 e 2016

REGIĀO GEOGRÁFICA

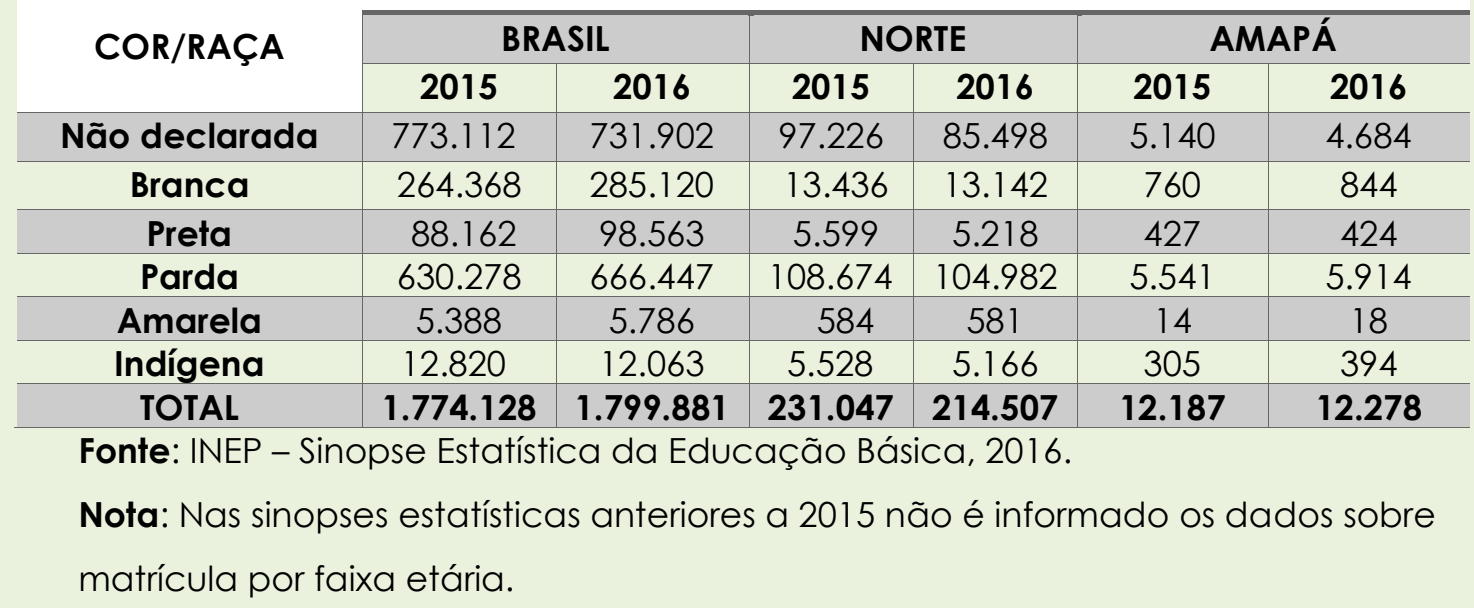

Os dados da tabela 2 evidenciam que a maioria da população masculina brasileira matriculada na EJA não declarou cor/raça $143,6 \%$ em 2015 e 40,7\% em 2016), esse mesmo movimento foi identificado no Norte e Amapá. Além disso, 35,5\% em 2015 (630.278) e 37\% em 2016 (666.447) da 
população se autodeclarou parda, e 14,9\% se autodeclarou branca em 2015 e 15,8\% em 2016. No Amapá também houve aumento nos percentuais de autodeclarados brancos passando de 6,2\% (760) em 2015 para 6,87\% (844) em 2016. Houve crescimento também nos autodeclarados indígenas que passou de 2,5\% em 2015 para 3,21\% (394) em 2016.

No tocante ao sexo feminino, movimento parecido também foi encontrado, conforme demonstra os dados da Tabela 3.

Tabela 3: Número de matrículas na EJA, do Sexo Feminino por cor/raça - Brasil, Norte e Amapá - 2015 e 2016

\begin{tabular}{|c|c|c|c|c|c|c|}
\multirow{2}{*}{ Cor/Raça } & \multicolumn{6}{c}{ REGIÃO GEOGRÁFICA } \\
\cline { 2 - 8 } & $\mathbf{2 0 1 5}$ & $\mathbf{2 0 1 6}$ & $\mathbf{2 0 1 5}$ & $\mathbf{2 0 1 6}$ & $\mathbf{2 0 1 5}$ & $\mathbf{2 0 1 6}$ \\
\hline Não declarada & 714.055 & 656.026 & 90.157 & 78.008 & 4.491 & 4.088 \\
\hline Branca & 269.237 & 279.890 & 14.147 & 13.664 & 784 & 884 \\
\hline Preta & 82.476 & 87.301 & 4.641 & 4.221 & 310 & 345 \\
\hline Parda & 632.848 & 640.745 & 108.967 & 102.126 & 5.726 & 5.715 \\
\hline Amarela & 5.494 & 5.954 & 599 & 555 & 15 & 16 \\
\hline Indígena & 13.631 & 12.377 & 5.574 & 5.315 & 278 & 374 \\
\hline TOTAL & $\mathbf{1 . 7 1 7 . 7 4 1}$ & $\mathbf{1 . 6 8 2 . 2 9 3}$ & $\mathbf{2 2 4 . 0 8 5}$ & $\mathbf{2 0 3 . 8 8 9}$ & $\mathbf{1 1 . 6 0 4}$ & $\mathbf{1 1 . 4 2 2}$ \\
\hline
\end{tabular}

Fonte: INEP - Sinopse Estatística da Educação Básica, 2016.

Entre a população feminina matriculada na EJA no país, predominam também pessoas que não declararam cor/raça em todas as regiões geográficas analisadas, entretanto, a população que se autodeclarou branca, preta, parda e amarela aumentou em 2016 no Brasil. Já no Amapá, aumentaram as autodeclarações na cor/raça branca, preta, amarela e indígena. Ao analisarmos em percentuais, pretos e indígenas têm um percentual baixo, em contrapartida, um percentual de não declarados é alto para ambos os sexos, conforme os dados coletados nos anos de 2015 e 2016, considerando que esse estado, em sua origem, tem traços marcantes, sobretudo, de grupos étnicos indígenas e negros, devido a uma forte presença de etnias indígenas e comunidades quilombolas distribuídas nos municípios amapaenses.

De acordo com o PNAD, ao analisar a distribuição da população por cor/raça, sexo, do ponto de vista de gênero, as mulheres com 15 anos ou 
mais chegam a 2016 com uma taxa de analfabetismo de $7,0 \%$, enquanto para os homens 0 índice era de 7,4\%. Entre os homens jovens que não estudavam, a razão mais frequente para não estarem na escola foi o fato de estarem trabalhando 50,5\%. Além disso, 24,1\% deles disseram que não tinham interesse e $8,2 \%$, que já tinham concluído o nível de estudo que desejavam. Entre as mulheres, os motivos para não estudarem foram: trabalho $(30,5 \%)$; por ter que cuidar dos afazeres domésticos ou de criança, adolescente, idosos ou pessoa com necessidades especiais $(26,1 \%)$, e por não ter interesse (14,9\%). Destaque-se que a proporção de mulheres jovens que não estudavam para realizar afazeres domésticos ou cuidar de pessoas era 32,6 vezes superior à dos homens envolvidos nessas atividades. (IBGE 2016).

$\mathrm{Na}$ perspectiva étnica racial, embora tenha havido melhoras, constata-se que a taxa de analfabetismo em 2016, 14,7\% entre pretos e pardos é duas vezes superior àquela apresentada pelos brancos $7,3 \%$, dos 11,8 milhões de analfabetos existentes em 2016, 9,9\% eram negros (preto e pardo), enquanto os brancos (4,2\%), conforme mostram os dados do PNAD (2016).

Tanto no Brasil quanto no Amapá, a democratização educacional e acesso de grupos étnicos precisa ser discutido, haja vista que, segundo o documento preparatório para a IV CONFITEA, há a persistência de desigualdades sócio-étnico-raciais, de gênero, do campo, das periferias urbanas, entre outros, no processo histórico-estrutural da sociedade. Entre essas e outras questões pertinentes precisam ser superadas, visto que é um compromisso político do Estado brasileiro para avançar no direito à educação de jovens e adultos (EJA).

Quando investigamos a distribuição das matrículas por dependência administrativa no Amapá, no período de 2010 a 2016, observamos que a rede estadual e municipal são quem mais oferta a modalidade da EJA no estado, conforme evidencia a Tabela 4 abaixo: 
TABELA 4 - Número de Matrículas por dependência administrativa, no Amapá 2010 a 2016

\begin{tabular}{|c|c|c|c|c|c|}
\hline ANO & Federal & Estadual & Municipal & Privada & TOTAL \\
\hline $\mathbf{2 0 1 0}$ & 0 & 17.579 & 4.977 & 921 & 23.477 \\
\hline $\mathbf{2 0 1 1}$ & 0 & 19.257 & 4.637 & 899 & 24.793 \\
\hline $\mathbf{2 0 1 2}$ & 0 & 18.637 & 4.326 & 1.169 & 24.132 \\
\hline $\mathbf{2 0 1 3}$ & 54 & 17.403 & 4.433 & 1.037 & 22.927 \\
\hline $\mathbf{2 0 1 4}$ & 139 & 17.071 & 4.637 & 1.161 & 23.008 \\
\hline $\mathbf{2 0 1 5}$ & 101 & 18.158 & 4.076 & 1.456 & 23.791 \\
\hline $\mathbf{2 0 1 6}$ & 101 & 17.705 & 4.379 & 1.515 & 23.700 \\
\hline
\end{tabular}

Fonte: INEP/Sinopse Estatística da Educação Básica - 2010 a 2016.

De acordo com os dados coletados acima, o número de matrículas no Amapá, nas dependências administrativas da rede estadual de ensino é maior comparado às outras dependências, revelando que as escolas estaduais são as principais instituições que oferecem a EJA no Amapá inclusive, conforme os dados coletados, oferta também a EJA profissionalizante (266 matrículas nas escolas estaduais são para essa modalidade, conforme Censo da educação básica em 2016).

Outra situação notada é que, entre 2010 a 2016, os números de matriculados nas dependências administrativas da rede privada vêm crescendo cada vez mais no estado, passando de 921 para 1.515 em 2016. Um fator que chama a atenção (e está em evidência no Brasil) é quanto à diminuição das matrículas da EJA do estado, que no período analisado demonstrou oscilação nos números de matrículas, por motivos que merecem ser estudas em outros trabalhos acadêmicos.

Nas tabelas seguintes, é possível evidenciar em que etapas de ensino estão sendo matriculados os alunos da EJA no Amapá. A tabela 5 evidencia a distribuição das matrículas no ensino fundamental, no período de 2010 a 2016, onde observamos que a maior quantidade de matrículas está nos anos finais. 
TABELA 5 - Número de matrículas na EJA no ensino fundamental no Amapá - anos iniciais/ anos finais 2010 a 2016

\begin{tabular}{l|c|c|c|c|c|c|c|c|c|c}
\hline \multirow{2}{*}{ ANO } & \multicolumn{4}{c}{ DEPENDÊNCIA ADMINISTRATIVA } & \multicolumn{5}{c}{ DEPENDÊNCIA ADMINISTRATIVA } \\
\cline { 2 - 13 } & \multicolumn{4}{c|}{ ANOS INICIAIS } & \multicolumn{4}{c}{ ANOS FINAIS } \\
\cline { 2 - 12 } & Federal & Estadual & Municipal & Privada & Total & Federal & Estadual & Municipal & Privada & Total \\
\hline $\mathbf{2 0 1 0}$ & 0 & 2.821 & 2.283 & 192 & 5.296 & 0 & 8.828 & 2.617 & 356 & 11.801 \\
\hline $\mathbf{2 0 1 1}$ & 0 & 3.946 & 2.195 & 188 & 6.329 & 0 & 8.553 & 2.364 & 375 & 11.292 \\
\hline $\mathbf{2 0 1 2}$ & 0 & 3.242 & 2.042 & 303 & 5.587 & 0 & 8.313 & 2.284 & 433 & 11.030 \\
\hline $\mathbf{2 0 1 3}$ & 0 & 3.337 & 2.118 & 171 & 5.626 & 0 & 7.707 & 2.315 & 443 & 10.465 \\
\hline $\mathbf{2 0 1 4}$ & 0 & 3.050 & 2.291 & 311 & 5.652 & 0 & 7.246 & 2.346 & 432 & 10.024 \\
\hline $\mathbf{2 0 1 5}$ & - & - & - & - & - & - & - & - & - & - \\
\hline $\mathbf{2 0 1 6}$ & - & - & - & - & - & - & - & - & - & - \\
\hline
\end{tabular}

Fonte: INEP - Sinopse Estatística da Educação Básica, 2010 a 2016.

Nota: As sinopses de 2015 e 2016 não especificam as matrículas por anos iniciais e finais.

Conforme a tabela acima, retrata a EJA nos seus respectivos níveis que a ofertam nos anos iniciais e finais do ensino fundamental, e de acordo com os dados, a rede Estadual de Ensino teve um crescimento destacável nos anos iniciais em 2011, porém, nos anos seguintes os números vieram diminuindo. Em 2015 e 2016 apesar de não ser possível identificar as matrículas nos anos iniciais e finais do ensino fundamental, entretanto, o Censo da Educação Básica mostrou que o total de matrículas foi de 14.935 em 2015 e 14.005 no ano seguinte.

No que se refere aos anos finais, a rede Estadual destacou-se no ano de 2010, porém, nos anos seguintes esse número diminuiu, em contrapartida em 2016 houve um aumento significante. Comparando os anos iniciais e finais nota-se que a rede privada de ensino, aumentou a oferta de matrículas, paralelamente a rede municipal apresentou um movimento oscilatório durante os anos pesquisados.

Ao analisarmos o quantitativo de matrículas no ensino médio amapaense, verificamos que esse só tem aumentado no período analisado. 
TABELA 6 - Número de matrícula na EJA no Ens. Médio Presencial no Amapá -2010 a 2016

ANO

DEPENDÊNCIA ADMINISTRATIVA

\begin{tabular}{|c|c|c|c|c|c|}
\cline { 2 - 6 } & FEDERAL & ESTADUAL & MUNICIPAL & PRIVADA & TOTAL \\
\hline $\mathbf{2 0 1 0}$ & 0 & 5.759 & 0 & 311 & $\mathbf{6 . 0 7 0}$ \\
\hline $\mathbf{2 0 1 1}$ & 0 & 6.758 & 0 & 336 & $\mathbf{7 . 0 9 4}$ \\
\hline $\mathbf{2 0 1 2}$ & 0 & 6.615 & 0 & 433 & $\mathbf{7 . 0 4 8}$ \\
\hline $\mathbf{2 0 1 3}$ & 54 & 6.102 & 0 & 423 & $\mathbf{6 . 5 7 9}$ \\
\hline $\mathbf{2 0 1 4}$ & 139 & 6.630 & 0 & 418 & $\mathbf{7 . 1 8 7}$ \\
\hline $\mathbf{2 0 1 5}$ & 28 & 7.440 & 0 & 506 & $\mathbf{7 . 9 7 4}$ \\
\hline $\mathbf{2 0 1 6}$ & 0 & 8.275 & 0 & 667 & $\mathbf{8 . 9 4 2}$ \\
\hline
\end{tabular}

Fonte: INEP/Sinopses Estatísticas da Educação Básica (2010, 2011, 2013, 2014, 2015e 2016) Nota: *No ano de 2016 a sinopse estatística não especifica as matrículas em presencial e à distância, somente o total de matriculas nesse nível de ensino.

No que diz respeito aos números de matriculados na EJA no ensino presencial no Amapá, nos anos de 2010 a 2016, nas respectivas dependências expressas na tabela acima mostram que em 2016 o número de matrículas teve um aumento significativo em comparação ao ano de 2010. Ganha destaque o aumento nas matrículas na esfera privada que dobrou o quantitativo no período analisado.

Outro aspecto que chama atenção é quanto às matrículas na esfera federal, que além de trazer variações significativas, apresentou quantitativos nos anos de 2013 a 2015. Em contrapartida, no ano de 2016 foi registrado o número de matrículas na EJA profissionalizante ${ }^{3}$ do setor federal do Amapá de 101 educandos matriculados e na rede estadual foi de 266 (totalizando 367 matrículas).

É importante frisar que no atual Plano Nacional de Educação 2014 2024, a EJA e o ensino médio, integrados à educação profissional estão presentes em diversas metas a serem cumpridas, o que permite inferir que a tendência dos próximos anos é o aumento nas matrículas que atendam essa integração. No estado do Amapá, no setor federal quem vem oferecendo EJA integrada à educação profissional é o Instituto Federal do Amapá - IFAP, que possui vários cursos ofertados, inclusive nos campi do interior do estado.

3 O quantitativo de matrículas da EJA profissionalizante não foi contabilizado nos dados da Tabela 6. 


\section{CONSIDERAÇÕES FINAIS}

Ao analisarmos a trajetória socio histórica da EJA, desde a colonização, a Educação de adultos já era pensada. Todavia, era desigual e excludente. Apesar disso, por longos anos tal modalidade de ensino caracterizou-se como programa de alfabetização temporária e ineficaz, cuja finalidade principal era acabar com o analfabetismo no País.

A educação de jovens e adultos em sua história sempre ficou atrelada ao contexto político o que mostrava em certos momentos avanços e retrocessos. Sem a devida preocupação com a criticidade, autonomia, emancipação cultural do sujeito educando. Deve-se compreender que a EJA não é uma modalidade de ensino, sujeita apenas a uma metodologia tradicional, é necessário levar em consideração o contexto vivencial do aluno, não tratando como sujeitos ignorantes, nem tão pouco utilizando ferramentas pedagógicas infantis para o aprendizado.

Um aspecto que vem sendo notado na Educação de jovens e adultos é o processo de juvenilização, o que antes a EJA era destinado a pessoas adultas, trabalhadoras e idosos, em sua maioria vindas do interior. Hoje se vê um público cada vez mais jovem, da área urbana, advindo da escola regular por motivo de reprovação, evasão, fracasso escolar e que vê a EJA como forma de certificação e aceleração dos estudos.

De acordo com as pesquisas e dados coletados nas sinopses da Educação básica 2016, o fenômeno da juvenilização é presente no Estado do Amapá, desde 2010 esse percentual vem crescendo cada vez mais tanto no Amapá, quanto no Norte e Brasil. Partindo dessa premissa, é de suma importância reconhecer que a juvenilização da EJA agrega uma concepção de mundo de pessoas que possuem tempos biológicos, características e sociológicos diferentes de um adulto ou idoso, distinguindose no seu processo educacional. Além de uma condição social, racial e cultural específicos, que necessitam estar claros para que a escola tenha condições de se adequar a diversidade que a EJA precisa.

Com a aprovação do FUNDEB e a integração da EJA a educação básica como uma modalidade de ensino que possui especificidades 
próprias, representou um salto em termos de políticas públicas de educação, entretanto é perceptível um processo de diminuição de matrículas na EJA, fato que precisa ser investigado em pesquisas futuras.

Portanto, democratizar o acesso à educação a todos, independentemente de cor, raça, gênero, faixa etária, é um desafio que precisar ser conquistado para assim concretizar uma educação libertadora, critica, democrática que esteja na perspectiva de educação ao longo da vida.

\section{REFERÊNCIAS}

AMAPÁ. Lei n 2.222, de 31 de agosto de 2017. Disponível em: http://www.al.ap.gov.br/ver_texto_lei.php?iddocumento=80614. Acesso em: 08 out 2018.

BRASIL. Lei de Diretrizes e Bases da Educação 9.394/96. Brasília, DF: Senado Federal, Coordenação de Edições Técnicas 2017. Disponível em:

<http://www2.senado.leg.br/bdsf/bitstream/handle/id/529732/lei_de_diretrize s_e_bases_led.pdf $>$. Acesso em: 01 mai 2018.

BRASIL. Parecer CNE/CEB 11/2000- Conselho Nacional de Educação/Câmara de Educação Básica. Disponível em:

<http://portal.mec.gov.br/cne/arquivos/pdf/pceb011_00.pdf>. Acesso em: 31 mar 2018.

BRASIL. Constituição da República Federativa do Brasil. 1988. Brasília, DF: Senado Federal: Centro Gráfico, 1988. 292 p.

BRASIL. Brasil. Estatuto da criança e do adolescente: Lei n. 8.069, de 13 de julho de 1990, e legislação correlata. - 13. ed. - Brasília: Câmara dos Deputados, Edições Câmara, 2015.

BRASIL. Estatuto do idoso. Brasília (DF): Senado Federal, 2003. www2.senado.leg.br/bdsf/bitstream/handle/id/70326/672768.pdf. Acesso em: 06 out 2018.

CARVALHO, R. V. A juventude na Educação de Jovens e Adultos: uma categoria provisória ou permanente. 2009. Disponível em:

http://educere.bruc.com.br/arquivo/pdf2009/2937_1947.pdf. Acesso em 20 mai 2018.

CUNHA, L. de O.; DAMASCENO, B. M. dos S. R.; CORTEZ, B. C. Educação de jovens e adultos: painel histórico e condições atuais. 2012. Disponível em: 
<http://editorarealize.com.br/revistas/fiped/trabalhos/14d4029c4c875a193a8 3864083273806_2231.pdf>. Acesso em 19 de mar 2018.

DIAS, A. de S. Educação de Pessoas Jovens, Adultas e Idosas: reflexões e apontamentos conceituais na perspectiva da transformação material. In: BRITO, Â. do C. U.; DIAS, A. de S. (Orgs.). Educação e Diversidade na Amazônia: práticas, reflexões e pesquisas. Curitiba-PR: CRV, 2017.

DI PIERRO, M. C.; JOIA, O.; RIBEIRO, V. M. Visões da educação de jovens e adultos no Brasil. Cadernos Cedes, v. 21, n. 55, p. 58-77, 2001.

DI PIERRO, M. C. Perdemos 3,2 milhões de matrículas na Educação de Jovens e Adultos. In: ÉPOCA. Entrevista em 2706 2016. Disponivel em: https://epoca.globo.com/ideias/noticia/2016/06/maria-clara-di-pierroperdemos-32-milhoes-de-matriculas-na-educacao-de-jovens-e-adultos.html. Acesso em: 17 ago 2018.

GIL, A. C. Métodos e Técnicas de Pesquisa Social. São Paulo: Atlas. 1987

GHIRALDELLI JR., P. "Entrevista: O Plano do heroísmo". In. Revista Educação n. 129, Janeiro 2008. São Paulo: Editora Segmento, p. 78.

HADDAD, S.; DI PIERRO, M. C. Escolarização de Jovens e Adultos. 2000.

Disponivel em: http://www.scielo.br/pdf/rbedu/n14/n14a07. Acesspo em: 20 abr 2018.

IBGE. PNAD Contínua 2016: $51 \%$ da população com 25 anos ou mais do Brasil possuíam apenas o ensino fundamental completo. Disponível em:

<https://agenciadenoticias.ibge.gov.br/agencia-noticias/2013-agencia-denoticias/releases/18992-pnad-continua-2016-51-da-populacao-com-25-anosou-mais-do-brasil-possuiam-apenas-o-ensino-fundamental-completo.html>. Acesso em 04 mai de 2018.

INEP. Sinopses Estatísticas da Educação Superior. 2010 a 2016. Disponível em: www.inep.gov.br. Acesso em: 10 abr 2018.

MACHADO, M. M. A trajetória da EJA na década de 90: políticas públicas sendo substituídas por solidariedade. In: Reunião Anual da ANPED, v. 21, p. 59-73, 1998. Disponivel em: forumeja.org.br. Acesso em: 10 abr 2018.

MACHADO, M. M. O aluno. IN: HADDAD, S. Educação de jovens e adultos no Brasil (1986-1998). Mec, 2002.

https://www.inesul.edu.br/site/documentos/serie_estado_conhecimento.pdf

MONTEIRO, A. L.; MOURA, A. P. M. de. A história identitária dos alunos da EJA e o perfil do profissional que atua nessa modalidade. In: Fórum Internacional de Pedagogia-IVFIPED. Campina Grande, REALIZE Editora, 2012. 
NASCIMENTO, S. M. do. Educação de jovens e adultos EJA, na visão de Paulo Freire. 2013. Monografia, Universidade Tecnológica Federal do Paraná, Paranavaí, 2013.

PAIVA, V.P. Educação popular e educação de adultos. São Paulo: Loyola, 1987.

RIBEIRO, P. C. A atuação da coordenação pedagógica frente ao fenômeno de juvenilização da educação de jovens e adultos numa escola pública estadual. Trabalho de Conclusão de Curso - Colegiado de Pedagogia. Universidade do Estado do Amapá. 2017.

UNESCO. Marco de Ação de Belém. Brasília: UNESCO, 2010. unesdoc.unesco.org/images/0018/001877/187787por.pd

OLIVEIRA, I. A. de. As Políticas de Educação de Jovens e Adultos no Séc. XXI: diretrizes dos documentos demarcatórios em curso. In: Arquivos do Centro de Documentação e Memória da Educação de Jovens e Adultos da Amazônia. Belém-PA: UEPA, 2011

SOUZA, G. L. R.; SILVA, L. A. da. A Educação de Jovens e Adultos como Instrumento de Transformação Social. 2011 . Disponivel em: periodicos.cesg.edu.br/index.php/educacaoecultura/article/viewFile/74/100 . Acesso em: 18 abr 2018.

SILVA, N. da. Ser "adulto": alguns elementos para a discussão deste conceito e para a formação de professores de "adultos. 2004. Disponivel em:

http://www.jpv.pt/millenium/Millenium29/35.pdf. Acesso em: 06 out 2018.

SOARES, V. C. Curso de gestão social de políticas educacionais em EJA.

Plano de intervenção EJA - Amapá, 2010. Disponível em:

forumeja.org.br/sites/forumeja.org.br/files/plano_estrategico_amapa2010.do c. Acesso em: 17 ago 2018.

SOARES, L. Diretrizes Curriculares Nacionais: Educação de Jovens e Adultos. Rio de Janeiro: DP\&A, 2002.

SOEK, A. M. Fundamentos e metodologia da educação de jovens e adultos. Curitiba: Editora Fael, 2012. 